\title{
INVENTÁRIO DO ABISMO ${ }^{1}$
}

\author{
Inventory of abysm
}

\section{Eliane Robert Mora es ${ }^{2}$}

Cento e vinte dias, seiscentas paixões. Quatro meses de libertinagem, quatro classes de vícios. A cada dia, cinco modalidades, somando cento e cinquenta por mês. Para dar conta dessas cifras, uma comitiva formada por quarenta e seis pessoas, distribuídas em oito categorias distintas, das quais sete pertencem à classe dos súditos. Oito meninos, oito meninas e oito fodedores. Quatro criadas e seis cozinheiras. Quatro esposas. Quatro narradoras. Por fim, na classe dos senhores, os quatro libertinos que sempre merecem designação individualizada: Curval, Durcet, Blangis e o Bispo.

A esses números - que apresentam ao leitor "a narrativa mais impura já escrita desde que o mundo existe" -, somam-se outros tantos que servem invariavelmente para precisar, com a maior exatidão possível, as atividades levadas a termo no castelo de Silling. No capítulo dos horários, por exemplo, a jornada é inflexível : os devassos devem acordar diariamente às dez horas da manhã; às onze é servido o desjejum; segue-se a inspeção dos haréns e, entre uma e duas da tarde - "e nem mais um minuto", adverte o narrador -, eles permanecem na capela devotada às volúpias coprofágicas. Das duas às três, durante a refeição dos súditos, os senhores descansam na sala de conversação. Seu almoço dura exatamente duas horas e, uma vez terminado, há espaço para

1 Este texto, em versão reduzida, foi publicado originalmente como apresentação à edição brasileira do romance do marquês de Sade, Os 120 Dias de Sodoma, tradução de Alain François, São Paulo, Iluminuras, 2006.

2 Eliane Robert Moraes é Doutora em Filosofia pela USP, professora titular de Estética e Literatura na PUC-SP e no Centro Universitário Senac-SP. Publicou, dentre outros, os livros Sade - A felicidade Libertina (Imago, 1994), O Corpo Impossível (Iluminuras/Fapesp, 2002) e Lições de Sade - Ensaios sobre a imaginação libertina (Iluminuras, 2006). E-mail: elianemoraes@uol.com.br

Rev. Filos., v. 18 n.23, p.. 81-86, jul./dez. 2006 
um repouso de quinze minutos. Às seis em ponto a comitiva se reúne na Câmara de Assembléias para dar início aos trabalhos do dia, que se prolongam por quatro horas. A ceia é servida às dez da noite, seguida de uma orgia que deve cessar pontualmente às duas da madrugada, quando todos se recolhem.

O protocolo dos horários talvez baste para sugerir a relevância da precisão numérica nesse livro que, a começar pelo título, opera com uma prodigiosa quantidade de algarismos, sinais, medidas, listas e toda sorte de cálculos. Nada escapa à contabilidade do quarteto de Silling, que registra desde o número de garrafas de vinho saboreadas pelos senhores em uma refeição até a quantia de carne branca ingerida por um súdito cujas fezes serão servidas na ceia; desde as proporções dos órgãos sexuais dos fodedores até o inventário de bundas disponíveis para uma orgia; desde o total de chicotadas recebidas pelos súditos em uma noite até o cômputo das mutilações realizadas ao longo de um mês. Nada escapa a essa contabilidade porque, ao lado das cenas lúbricas, as operações aritméticas são fundamentais para singularizar o "catálogo de perversões" que inaugura a obra do marquês de Sade sob o título de Os 120 Dias de Sodoma.

Vale lembrar que, assim como o sexo, os números são inequívocas fontes de prazer no mundo do deboche. Antes de mais nada porque a enumeração sadiana visa a explicitar as cifras do gozo e, por tornar manifesto o que normalmente se vela, representa uma contestação aos discursos alusivos que só se referem a matérias sexuais por meio de subterfúgios retóricos. Ali onde o código literário do século XVIII não tolera qualquer enunciação frontal, sujeitando a metáfora ao pudor, o marquês tem a ousadia de introduzir o mais extremo realismo, associando-o aos mais bizarros caprichos da imaginação. Ou, dizendo de outro modo, a enumeração libertina se traduz em prazer por implicar sempre uma contravenção - seja ela literária, moral ou até mesmo física, já que o narrador almeja "aquecer o leitor a ponto de lhe custar algum sêmen".

Além disso, convém recordar que a fantasia libertina também se alimenta amiúde dos balanços das realizações levadas a cabo por seus artífices. "Nada excita mais do que uma grande quantidade" diz um dos senhores de Silling ao tomar ciência do total de vítimas de uma jornada particularmente bem-sucedida, reiterando a satisfação que as altas cifras podem lhes proporcionar. Por certo, a quantidade 
evoca a abundância, o luxo, o poder e outras figuras da riqueza sem as quais esses personagens nem ao menos poderiam imaginar as "extravagâncias da luxúria" a que se abandonam diariamente.

De fato, a amplitude da dilapidação que está no horizonte das atividades da libertinagem supõe reservas sem fim, sejam elas de dinheiro, de energia, de corpos, ou do que mais for necessário para sua plena realização. Mas, uma vez contabilizadas, as somas esbanjadas em função do gozo físico são repostas em um plano simbólico que opera significativa inversão de sinais: o que foi dilapidado tornase então objeto de acumulação. Lê-se na $42^{a}$ modalidade das paixões complexas : "Encontra-se com trinta mulheres por dia e faz com que cada uma delas cague em sua boca; come o cagalhão das três ou quatro mais belas. Repete essa diversão cinco vezes por semana, o que totaliza sete mil e oitocentas mulheres por ano. Quando Champville o conhece ele já tem setenta anos de idade e está em atividade há cinqüenta". Como que convidando o leitor a partilhar desses prazeres, Sade lança a ele a tarefa de completar a conta para chegar a uma cifra ainda mais surpreendente.

$\mathrm{Na}$ aventura libertina há sempre esse desejo de abarcar as maiores quantidades, de alcançar os marcos inatingíveis, de realizar a derradeira somatória, insinuando a aposta em um projeto que busca a saturação. Tome-se, como exemplo, uma das paixões assassinas mais insólitas dos 120 Dias : "um grande devasso adora dar bailes, mas sob um teto preparado que desaba quando o salão está cheio, provocando a morte de quase todos os presentes. Se vivesse sempre na mesma cidade, seria descoberto, mas muda com freqüência, de forma que só costuma ser descoberto depois do qüinquagésimo baile”. À bizarra contabilidade dessa cena, traço freqüente da ficção sadiana, some-se ainda outra modalidade de paixão que o mesmo romance apresenta de forma tão direta quanto sucinta, para o completo desconforto do leitor: "Um incestuoso, grande apreciador da sodomia, para reunir esse crime ao de incesto, de assassinato, de estupro, de sacrilégio e de adultério, se faz enrabar por seu filho com uma hóstia no cu, estupra a filha casada e mata a sobrinha".

Com certeza, não é preciso mais que essas duas paixões para se perceber que, também no capítulo da saturação, a matemática sadiana opera em paralelo à economia dos corpos, respondendo à mes-

Rev. Filos., v. 18 n.23, p.. 81-86, jul./dez. 2006 
ma exigência de preencher todos os espaços vazios. Daí o privilégio dado às adições e multiplicações, mesmo quando se trata de dar conta do que foi desmembrado ou subtraído. Contudo, como "um excesso sempre conduz ao outro", segundo a categórica síntese de Curval, a saturação do deboche não resulta em qualquer empenho de esgotamento, mas sim na manutenção da própria contabilidade. Ou, se quisermos, na manutenção do excesso.

Saturar significa inventariar, enumerar, catalogar. Trata-se de criar um catálogo, o mais completo possível, contendo toda sorte de elementos disponíveis que, de alguma forma, possam servir à libertinagem. Uma vez realizado esse inventário, a possibilidade do deboche fica garantida, pois dele depende o inesgotável jogo ao qual os personagens sadianos se abandonam com rigor e obstinação, revelando o sentido maior de suas elocubrações aritméticas: a combinatória.

O intento combinatório implica uma recusa frontal ao sentimento amoroso, já que sua realização tem por base a indiferenciação entre os sujeitos, a substituição de uns pelos outros, a intercambialidade dos corpos. Fiel a esse princípio, o sistema de variações da libertinagem destina-se a criar o máximo de possibilidades entre os elementos disponíveis, vale dizer, entre aquilo que o quarteto prefere chamar de "objetos da luxúria". Ora, dado que o gozo dos devassos deriva das quantidades, como já observou Marcel Hénaff, as combinações se tornam a solução ideal para lhes garantir o mais alto grau de rentabilidade do sistema: além de esgotar o plano previsto, elas criam condições para a ocorrência da surpresa, valor libertino por excelência.

Combinar, variar, diversificar: é precisamente essa a lógica do gigantesco balanço sexual proposto por Sade, cujo principal fundamento reside nos detalhes que diferenciam as paixões. São portanto essas variações resultado das combinatórias mais improváveis e sutis, que o narrador convida o leitor a apreciar na notável introdução do livro: "Quanto à diversidade, esteja seguro de que é exata; estude bem aquela paixão que à primeira vista parece assemelhar-se a uma outra e verá que a diferença existe e que, por ínfima que seja, ela possui precisamente esse refinamento, esse toque que distingue e caracteriza o gênero de libertinagem sobre o qual se discorre aqui".

Tal qual um inventário do abismo, as jornadas sadianas submetem essas variações à prova da insaciedade libertina, para criar um catálogo paradoxal que, no intento de registrar todas as possibilidades 
do sexo, termina por render-se ao ilimitado do desejo. ${ }^{3}$ É o que se testemunha neste romance: se, na introdução, o marquês promete oferecer seiscentas paixões, delimitando um número redondo, já no final do livro, o projeto de exatidão numérica não se realiza. Basta notar que a classe de paixões assassinas não completa as cento e cinquenta modalidades previstas, conforme o próprio autor assinala : "148. A última. (Verificar por que faltam essas duas, estavam todas no rascunho.) O último senhor que se abandona à última paixão que nós designaremos sob o nome de inferno foi... " Com essa falta, a lista não se conclui, abrindo-se sobre um horizonte indeterminado: assim como o corpo, a cifra é precipitada ao seu ponto de fuga.

Aí reside a radicalidade da "filosofia lúbrica" de Sade, que reconcilia a abstração aritmética com a irredutível imanência do corpo para recusar a milenar separação entre idéia e matéria. Aí reside a particularidade desse monumental catálogo, franqueado à vertigem da imaginação. Cento e vinte dias, quinhentas e noventa e oito paixões. O desejo lançado ao infinito.

\section{Referências}

BUFFAT, Marc. "Préface". In: SADE, Marquês de. Lettres à sa femme, Paris: Babel, 1997.

HÉNAFF, Marcel. L'invention du corps libertin. Paris: PUF, 1978.

LÉLY, Gilbert. Vie du Marquis de Sade. Paris: Gallimard, 1978. Tomo, I-II.

MORAES, Eliane Robert. "A leitura na alcova" e "A cifra e o corpo". In:

3 Gilbert Lély sugere semelhante idéia numa feliz associação desse romance com o Livro das Mil e uma Noites - cuja noite adicional que se acrescenta ao número "mil", segundo Jorge Luís Borges, apontaria a eternidade -, aludindo aos "cento e vinte e um dias de Sodoma", que estão no horizonte do primeiro romance de Sade. Assim, esses textos tão distintos - mas, de uma forma ou outra, ambos implicados na sensibilidade libertina do século XVIII - apontam precisamente para o interminável, seja o da narrativa para Sherazade, seja o do vício para Sade. Citado por Pascal Pia (org.), Dictionaire des Euvres Érotiques, Paris, Mercure de France, 1971, p. 91).

Rev. Filos., v. 18 n.23, p.. 81-86, jul./dez. 2006 
Lições de Sade: Ensaios sobre a imaginação libertina. São Paulo, SP: Iluminuras, 2006.

PAUVERT, Jean-Jacques. Sade vivant: tomo II. Paris: Robert Laffond, 1989. PIA, Pascal (org.). Dictionaire des Euvres Érotiques. Paris: Mercure de France, 1971.

SADE, Marquês de. Os 120 Dias de Sodoma. Tradução de Alain François. São Paulo, SP: Iluminuras, 2006.

Oeuvres completes. Paris: Pauvert, 1986-1990.

Recebido em/Received in: 15/05/2006 Aprovado em/Approved in: 20/06/2006 